\title{
Intertextuality and Directionality in the Communication Discourse of a Translation Activity
}

\author{
Bo Wang (Corresponding author) \\ Centre for Translation Studies, The Hong Kong Polytechnic University \\ Hung Hom, Kowloon, Hong Kong \\ E-mail: bo.wang@connect.polyu.hk
}

Received: 18-08- 2014

Published: 01-05- 2015
Accepted: 28-11- 2014

doi:10.7575/aiac.ijalel.v.4n.3p.31
Advance Access Published: December 2014

URL: http://dx.doi.org/10.7575/aiac.ijalel.v.4n.3p.31

\begin{abstract}
This paper reports on a study based on a corpus of written professional discourses. Both e-mails and doumails (a specific sort of e-mail used at the website of douban) between a translator and several editors from a publishing house during a translation activity on book publication are collected as data for the analysis. The purpose of compiling the corpus is to describe professional literacy by means of identifying the different types of intertextuality found as well as the directionality of intertextuality in discourse flows. Intertextuality is signaled, and some frequent-occurred phraseologies are found within the corpus. The study also quantifies the types and the directionality of intertextuality by distinguishing prior, current, and predicting intertextual references. The prevalence of intertextuality could thus be identified. It is expected that this study could shed some light on researches in professional discourses and the training of novice professionals with communication skills. In addition, this study also reveals the power relationship between the translator and editors, and would be helpful to the description of translation activities.
\end{abstract}

Keywords: corpus, professional discourse, intertextuality, discourse flow, directionality, translation activity

\section{Introduction}

Discourse, according to Celce-Murcia and Olshtain (2000: 4), "is an instance of spoken or written language that has describable internal relationships of form and meaning ... that relate coherently to an external communicative function or purpose and a given audience/interlocutor." It is also suggested that the function and purpose of the discourse could only be determined by taking context and participants into consideration.

The present study is based on a corpus of written professional discourses. The written texts in the corpus are e-mails and doumails (a specific sort of e-mail used at douban website) during a translation activity between the participants, i.e. the translator of a book called Pantone: The 20th Century in Colour and several editors from a publishing house. All written e-mail and doumail discourses related to the translation of the book are included in the corpus. From the initiation of the translation activity to the successful publication of the book, the data offer the communication footprint of the five professionals involved. The purpose of compiling the corpus is to delineate professional literacy by means of identifying intertextuality as well as the directionality of intertextuality in the discourse flow.

As one of the research focuses in recent years, literacy has been used to describe the ways in which competence is gained in the proper written mode within certain contexts (Barton and Hamilton, 1998; Cheng and Kong, 2009; Clark and Ivanic, 1997; Gunnarsson, 1997; Rosemary, Roskos and Landreth, 2007; Searle, 2010; Spilka, 1993; Warren, 2011, 2013). According to previous studies on discourse, the world can be regarded as textually mediated (Barton and Hamilton, 1998; Warren, 2011, 2013). In a broad sense, literacy encompasses various contextual, discursive and textual elements for individuals to utilise, and global factors (e.g. socio-cultural parameters, organisational cultures, local factors) have all exerted their influences on literacy (Warren, 2011, 2013). In this way, the present prospective of this study is also in accord with critical discourse analysis in which the power relationship between language and society has been explored (Fairclough, 1989, 1992, 1995).

This paper concerns with professional literacy between translator and editors' e-mails. On one hand, the translation activity in this study has its own particular features which are different from other professional activities, such as the unequal division of power between the translator and editors, the role of translation brief and contract, the responsibility of editing, etc. The activity starts with the translator's inquiry of a job and ends with the successful publication of the book. On the other hand, e-mails are the primary means of communication between the professionals in this study. They provide us with information, and are meaningful in the present study of professional literacy. 


\section{Literature Review}

In the following part, the conception of intertextuality would be elaborated, with different typologies of intertextuality categorization introduced. Some significant studies in the literature are also reviewed, while some research gaps are expected to be identified.

\subsection{Intertextuality}

A discourse is part of a set of interconnected discourses, thus it never exists in isolation (Candlin and Maley, 1997; Warren, 2011, 2013). Within a discourse flow, the current discourse not only refers to prior discourses but also makes reference to predicted discourses. Therefore, all discourses are intertextual (Bhatia, 2004; Fairclough, 1992; Warren, 2011, 2013). As it is proved by previous studies (O'Connor, 2002; Warren, 2013), competence in intertextuality is a crucial feature of professional literacy. Therefore, it would be important for participants in a professional setting to master intertextuality, so as to carry out successful communication. Intertextuality is hence regarded as an important component of professional communicative competence (Cheng, 2009).

Discourse is not a discrete isolated event, it is the product of past, current, and predicted discourses. According to Devitt (1991: 336), "no text is single, as texts refer to one another, draw from one another, create the purpose for one another." Thus, a discourse is created and interpreted in relation to both prior and predicted discourses and needs to be appropriately situated within its respective discourse flow.

Various scholars have contributed to the classification of intertextuality (e.g., Bhatia, 2004; Devitt, 1991; Fairclough, 1992; Warren, 2013). Devitt (1991) has viewed intertextuality as a three-dimentional concept while examining the role and interaction of discourses in tax accounting. Three types of intertextuality are identified, i.e. generic intertextuality which occurs when a text draws upon previous texts written in response to similar situations, referential intertextuality which refers to "the reference within one text to another text" (p. 342), and functional intertextuality which "refers to the interaction of texts in the particular community" (p. 337).

Fairclough (1992) has suggested three categories of intertextuality, namely, sequential intertextuality which takes place when "different texts or discourse types alternate within a text" (p. 118), embedded intertextuality which occurs when a text or discourse type is clearly contained within the matrix of another, as well as mixed intertextuality, which means that texts or discourse types are merged in a more complex and less easily separable way.

In World of Written Discourse, Bhatia (2004: 126) has categorized intertextuality into the following six types: "(1) texts providing a context (e.g. a letter to which the one in question is a reply), (2) texts within and around the text (e.g. a chapter in the context of a book), (3) texts explicitly referred to in the text (e.g. references in academic journals), (4) texts referred to implicitly in the text (e.g. "The sun never sets over Lufthansa territory" used in an advertisement, with an implicit reference to "The sun never sets over the British Empire"), (5) texts embedded within the text (e.g. conversation within a story), and (6) texts mixed with the text (e.g. quotations, etc.)."

Warren's (2013: 15) categorization is largely based on that of Bhatia (2004). However, as Bhatia's first two types of intertextuality could be regarded as the characteristics of all discourse instead of the specific types of intertextuality, they are thus not included in Warren's study. Therefore, his four types of intertextuality are: "(1) explicit references (i.e. signals) to prior and/or predicted texts, (2) implicit references (i.e. signals) to prior and/or predicted texts, (3) embedding by means of paraphrase, summary, etc., (4) embedding in a text by means of direct quotes" (p.15).

\subsection{A Review on Previous Studies}

There have been various studies on intertextuality. These studies complement each other and differ in genre and mode (see Table 1).

Table 1. Some Studies on Intertextuality

\begin{tabular}{lll}
\hline study & genre & mode \\
\hline Candlin and Maley (1997) & discourse of dispute resolution & spoken \\
\hline Solin (2004) & public discourse & written \\
\hline Ho (2011) & $\begin{array}{l}\text { professional English teachers' request } \\
\text { e-mails }\end{array}$ & written \\
\hline Warren (2013) & business e-mails & written \\
\hline
\end{tabular}

Candlin and Maley (1997) examine the mediator discourse of alternative dispute resolution in divorce matters. The intertextual and interdiscursive elements are identified with their functions discussed. Intertextuality could reinforce our understanding on professional literacy, as it is found in the study that the meaning of utterances could sometimes be reformulated by the mediator. Some strategies adopted by the mediator in professional communication are identified, such as to create "favourable interpersonal meanings of cooperation and goodwill" (p. 219). 
Different from the analysis of spoken discourse in Candlin and Maley's (1997) study, Solin (2004: 267) analyzes the intertextual relations in public written discourse as "a form of mediation through which claims produced within one domain are taken up in other domains and travel across domains." The concept of intertextual chain has been applied to the analysis of the textual relations set up between the four institutions. It is found out that "causal claims are systematically strengthened when scientific and government claims are embedded into news reports. The assumption that intertextual chains are not a neutral form of mediation has been proved."

Studies on the intertextuality of e-mail discourse abound in the literature (e.g. Kankaanranta, 2006; Nickerson, 2000; O'Connor, 2002; Ho, 2011; Warren, 2011, 2013). For example, Ho (2011) investigates the intertextuality and interdiscursivity of the professional English teachers' request e-mails. In his approach, he summarizes the different pragmatic functions of the request e-mails, namely, "(1) distancing themselves from the discourse and thus diverting the possible forthcoming resentment to others; (2) convincing others to comply with the requests they made; (3) emphasizing selectively and strategically the various roles they were playing; and (4) managing rapport with the e-mail recipients" (Ho, 2011: 2534).

Warren (2013) compares professional literacy in two professions by studying the intertextuality in the e-mails from several discourse flows, and examines intertextuality in terms of types and directionality of use. His methodology is different from those in all previous studies. He distinguishes directionality of intertextuality into prior, current and predicting intertextual references, quantifies the number of words of each kind, and gives explanation to reasons that have caused the differences in number. His study not only stresses the importance of intertextuality but also provides a methodological procedure for future studies. It is not the first study that deals with discourse flow or intertextuality, but is the first study to quantify the types and directionality of intertextuality in e-mail communication.

The reviewed studies complement each other in that they have covered both the spoken and written mode of expression, and have explored intertextuality in various genres. It is suggested that by analyzing intertextuality and directionality, we can gain a deeper understanding of the nature and functions of professional discourse in various modes and contexts. Meanwhile, as Warren (2013) indicates, intertextuality varies in accordance with different communicative contexts and professions, which is worthwhile to be examined respectively.

Some research gaps have been identified after reviewing these studies. Firstly, though professional literacy in e-mail has been frequently examined, none of them are related to the profession of translation. The roles of participants in a translation activity have never been described by way of analyzing the intertextual features. Further, no study has ever followed Warren's (2013) quantitative methodology to the analysis of intertextual features. For this reason, the current study is greatly inspired by Warren's (2003) research.

\section{Purpose of the Study}

As it is seen from the review, few studies compare the different types and directionality of intertextuality in the communication discourse of a translation activity. In the present study, the following two questions are put forward:

(1) In the collected communication discourses, what are the types of directionality? What are the differences between the editors and the translator's discourse in this respect?

(2) What are the frequently used phraseologies in this communication discourse?

\section{Methodology}

According to Warren (2011: 93), a discourse flow could be defined as "a series of interconnected discourses which constitutes a coherent set of discourses based around a common theme". In the present study, after the data have been collected, they are placed in a discourse flow. As it is stated above, all discourses are situated on past, current and predicted discourses, so they are not isolated products.

The discourses within the discourse flow are categorized as internal and external, with the numbers of each categories calculated. Then the discourses are analyzed in terms of prior, current and predict intertextual references. The number of words has been calculated so as to examine the proportional usage of directionality of intertextuality in the data.

Intertextuality is analyzed following the pattern of the two examples. Prior texts are highlighted in bold, while predicted texts are underlined.

In the first example (doumail 1), the translator initiates the discourse by putting forward a request (line 4). He adopts instances of intertextuality that predict future texts. Then he enquires Zhang, the editor (who is a more powerful participant in the discourse) about the publishing plan (line 7) and further predicts future texts.

Example 1

1. From: Wang

2. To: Zhang

3. Sent: Feb 9, 2012 19:33 PM

4. Do you have any books that need a translator? I could do some work these days. 
5. Those with fewer pages would be better, such as 501 Great Writers,

6. The World History of Animation, and so on.

7. Are you planning to publish any of these books this year?

The following example (e-mail 11) is an internal e-mail from Zhang, the director to his staff, Ye. The translator's suggestions from a previous discourse have directly been cut and pasted here. Thus, a large amount of prior intertextual references are found in this discourse.

Example 2 (Discourse 16 - E-mail 11)

1. From: Zhang

2. To: Ye

3. Sent: May 12, 2012 10:20 AM

4. Subject: Re: Manuscript of a New Book

5. Hi, Ye T***. You'll be in charge of Pantone: The 20th Century in Colour, which

6. is translated by Wang. His e-mail is $\mathbf{w}^{* * * * * * * * * * @ 163 . c o m}$. Below are

7. his suggestions on editing the book.

8. And please note the following points:

9. Firstly, the numbers in the main body of the book are the original endnotes.

10. They are not arranged in order. I have checked all of them. Please make

11. sure that you would not delete them.

12. Secondly, I have added some notes to the manuscript. You'd better keep

13. them if there is enough space on those pages. I suggest that you don't

14. put them at the end of the book.

15. Thirdly, some of the items in the index have not appeared in the book.

16. You may need to delete them if possible.

17. Best wishes,

18. Zhang

Once the prior, current, and predicting intertextual references for translator and editors are quantified, they will be further discussed in the next section. Some frequent-used phraseologies would also be located with the help of a corpus software.

\section{Findings and Discussion}

\subsection{Intertextuality in a Discourse Flow}

The discourse in the discourse flow deals with one request on book translation. Five persons who work both inside and outside the publishing house are involved (Wang and Zhang are partners who work on book translation. As a section head of the publishing house, Zhang has several staff under his leadership, such as Liu, Ye, and Rao, who are all editors from the same publishing house.).

The discourse flow is initiated by Wang, who works as a translator and is trying to seek an opportunity for translating a book. Wang has put forward his request in a doumail and has received a reply. This request has triggered several doumails relating to the translation activity. After discussing with Zhang, they have chosen a book to work on. Then, Zhang demands Liu to make an arrangement on signing the contract. After the translation work has completed, Zhang further assigns Ye to be in charge of editing. Finally, Wang enquires Zhang about the publication progress, and receives Zhang's reply. When the book has been published, Rao gets in touch with Wang at Zhang's request.

This discourse flow consists of 26 discourses, 3 internal (i.e. between editors in the same publishing house) and 23 external (i.e. between editors and the translator), 10 doumails and 16 e-mails. Here I would present a summary of the discourse flow:

prior discourses $\rightarrow$ doumail 1 (external, From: Wang) $\rightarrow$ doumail 2 (external, From: Zhang) $\rightarrow$ doumail 3 (external, From: Wang) $\rightarrow$ doumail 4 (external, From: Zhang) $\rightarrow$ doumail 5 (external, From: Wang) $\rightarrow$ e-mail 1 (external, From: Zhang) $\rightarrow$ e-mail 2 (external, From: Wang) $\rightarrow$ e-mail 3 (external, From: Zhang) $\rightarrow$ e-mail 4 (internal, From: Zhang) $\rightarrow$ e-mail 5 (external, From: Liu) $\rightarrow$ e-mail 6 (external, From: Wang) $\rightarrow$ e-mail 7 (external, From: Wang) $\rightarrow$ e-mail 8 (external, From: Zhang) $\rightarrow$ e-mail 9 (external, From: Wang) $\rightarrow$ e-mail 10 (external, 
From: Zhang) $\rightarrow$ e-mail 11 (internal, From: Zhang) $\rightarrow$ doumail 6 (external, From: Wang) $\rightarrow$ doumail 7 (external, From: Zhang) $\rightarrow$ doumail 8 (external, From: Wang) $\rightarrow$ e-mail 12 (external, From: Ye) $\rightarrow$ e-mail 13 (external, From: Wang) $\rightarrow$ e-mail 14 (external, From: Ye) $\rightarrow$ doumail 9 (external, From: Wang) $\rightarrow$ doumail 10 (external, From: Zhang) $\rightarrow$ e-mail 15 (internal, From: Zhang) $\rightarrow$ e-mail 16 (external, From: Rao) $\rightarrow$ predicted discourses

In fact, there are prior discourses before the first doumail, while after e-mail 16, there would also be more predicted discourses. Within the discourse flow, "internal" and "external" discourses are relative to whether the subjects work inside the publishing house or not. The discourse flow might be incomplete, because the telephone calls inside the publishing house are not recorded and included, but it somehow conveys the complexity and interconnectedness of professional discourses.

\subsection{Directionality of Intertextuality}

The present study then quantifies the types and the directionality of intertextuality by adopting Warren's (2013) methodology on the distinction of prior, current, and predicting intertextual references. The following table illustrates the distribution of words used by the translator and the four editors in the discourse flow. The word number of prior, current, and predicting intertextual references has been calculated to examine the proportional usage of directionality of intertextuality in the data.

Table 2. The use of prior, current, and predicting intertextual references

\begin{tabular}{ccccc}
\hline & Prior & Current & Predicting & Total Words \\
\hline Translator & $\begin{array}{c}49 \\
(10.25 \%)\end{array}$ & $\begin{array}{c}249 \\
(52.09 \%)\end{array}$ & $\begin{array}{c}180 \\
(37.66 \%)\end{array}$ & $\begin{array}{c}478 \\
(100 \%)\end{array}$ \\
\hline \multirow{2}{*}{ Editors } & $\begin{array}{c}241 \\
(34.78 \%)\end{array}$ & $\begin{array}{c}179 \\
(25.83 \%)\end{array}$ & $\begin{array}{c}273 \\
(39.39 \%)\end{array}$ & $\begin{array}{c}693 \\
(100 \%)\end{array}$ \\
\hline
\end{tabular}

The examination of directionality has proved the prevalence of intertextuality. Both the translator and the editors' discourses have contained a great amount of intertextual features. In the editors' discourses, the directionality towards prior text is of a larger proportion (34.78\%), which is almost three times that of the translator's $(10.25 \%)$. This is because the editors have frequently responded to the translator by answering questions (58 words) or giving feedbacks (63 words). Moreover, they also do more cutting and pasting as well as citing a lot of prior discourses (120 words).

For the translator, the directionality towards current text is nearly twice that of the editors (52.09\% versus $25.83 \%$ ), as his discourses are largely focused on reporting work progress.

For both the translator and the editors, the proportions of directionality towards predicting text are quite similar (37.66\% versus $39.39 \%$ ). However, in the translator's discourses, directionality is more towards the predicting text instead of the prior text (37.66\% versus $10.25 \%)$, as the translator enquires and requests a lot.

Different from previous qualitative studies on intertextuality, which concentrates either on textual relations, communicative strategies or pragmatic functions, some qualitative findings are drawn from the discussion. Firstly, intertextuality and directionality in this process of communication between editors and translators have revealed the participants' power and identity. The editors, who retain more power, tend to command or make decisions. Take Zhang, the section head in the publishing house for instance, he is responsible for choosing the translator and the editor of the book, and he also makes final decision about the style of index in the book (e.g. "Wang Bo would be the translator of Pantone: The 20th Century in Colour." "You'll be in charge of Pantone: The 20th Century in Colour." and "I choose the first style of the index."). This has also contributed to the large number of predicted intertextual references. For the translator, who has to report his work progress according to the signed contract, he is relatively weak in power and has thus contributed a great deal of current intertextual references (e.g. "I am now translating the index of the book." "The numbers in the main body of the book are the original endnotes."). Secondly, the analysis has attempted to prove the suitability of the present analytical framework for the study of professional discourses. It would be worthwhile to adopt the same analytical tool and study professional literacy in other workplaces, and compare the differeces found among different jobs or contexts.

\subsection{Signalling Intertextuality in a Corpus}

As it is analyzed previously, intertextuality frequently occurs in the discourse flow. A discourse flow corpus was then compiled in order to signal intertextuality. The whole data for the corpus comprise about 1500 words. A word frequency list is then generated and compared with that of British National Corpus. Some key words have occurred solely or more frequently in this discourse flow corpus (e.g. Pantone, contract, please, may) and have thus been identified. And some of them are used to signal the frequent-occurred phraseologies in the discourse flow. 
Concordances, defined as "recurrent associated words/word classes" (Warren, 2011: 102), are examined to find out the frequent phraseologies. In this corpus, the most frequent phraseology is please + verb (see Figure 1), which is also consistent with the finding of Warren (2011). This phraseology is both used to refer to predicted discourses, such as please make sure ( 4 occurrences), please note ( 2 occurrences), please send ( 2 occurrences), please translate $(1$ occurrence), as well as to signal prior discourses, for example, please find (1 occurrence).

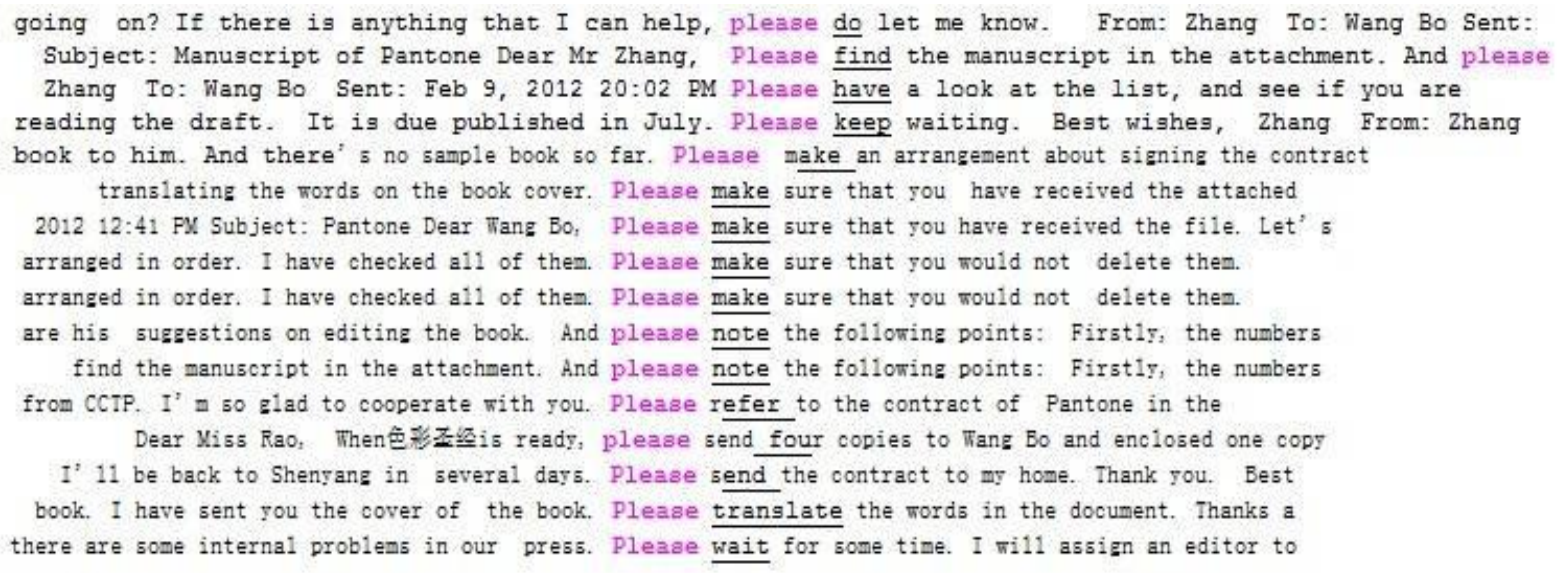

Figure 1. Instances of please + verb

Model verbs such as could, may and would are frequently found in the corpus. Together with subject pronoun and a verb, they have composed several frequent-occurred phraseologies (see Figure 2). And the most frequent phrases found are may + need ( 6 occurrences).

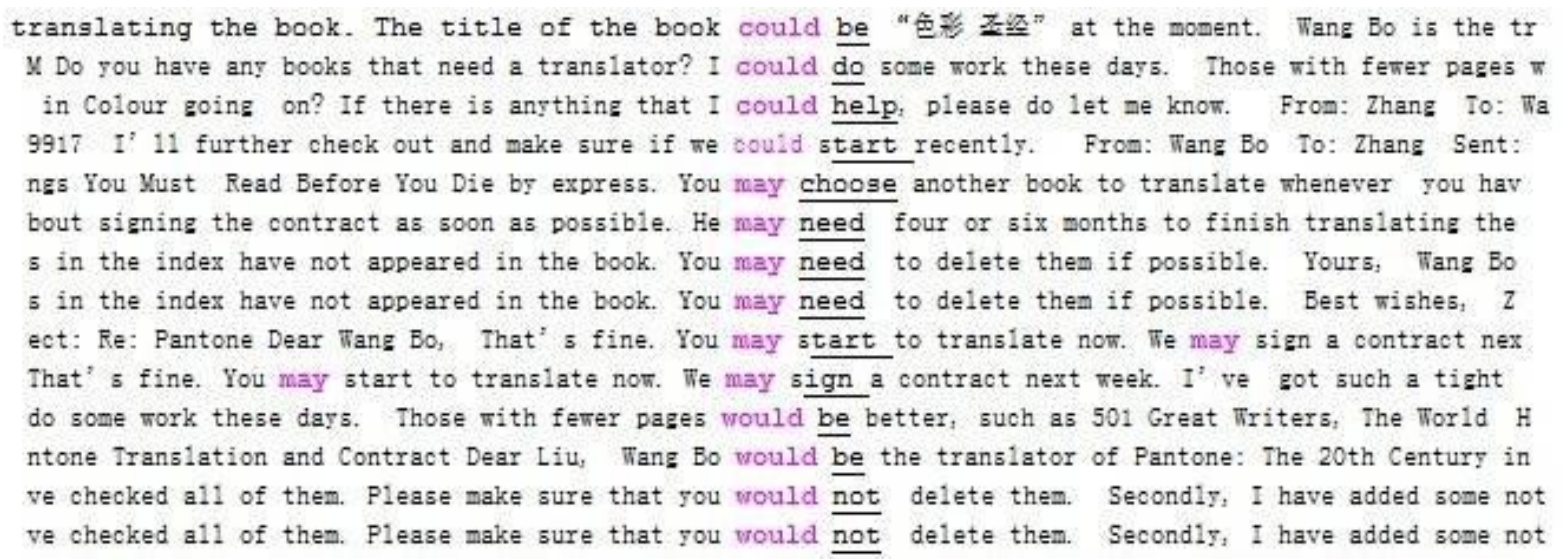

Figure 2. Instances of subject + could $/$ may/would + verb

As the data size for the present study is rather small, a limited amount of frequent occurred-phraseologies are found. However, these two phraseologies have revealed some features of professional literacy in that they both help e-mails to carry a softer tone. As a politeness marker, the word "please" has been generally used as a politeness strategy in request (Gao, 1999). Further, according to a study by David Qian (2005: 119) who investigates business professionals' opinions on business writing, some modal verbs are recommended in writing "to soften the tone so that the points would be easier to be accepted by the reader."

If we consider the background of the participants, the reason for using these two phraseologies could thus be explained. Both the editors and the translator are Chinese. The editors are from a publishing house in Beijing, and they have all received their bachelor degrees, according to the general requirement of employment in the publishing house. The translator is a doctoral student in Hong Kong, who is proficient in English. English, as a global lingua franca, has now been frequently used in China. It is taught since primary school and has been encouraged to be used in some of the work places in China. The two frequent-occurred phraseologies are both concerned with politeness in English. They have somehow reflected the politeness strategies adopted by the English learners from China, who have learned such strategies from their English classes at school and have extended these strategies in their writings (Lee, 2004). Both the frequent use of "please" and modal verbs may refer to one of the features of China English, which is a developing variety of World Englishes.

\section{Conclusion}

This study has proved the prevalence of intertextuality by examining a discourse flow collected from e-mails between a translator and several editors from a publishing house. By distinguishing prior, current, and predicting intertextual 
references, the study has also quantified the directionality of intertextuality, and explained the differences between the editors and the translator's discourses. The power relationship between translator and editors is partly revealed. Meanwhile, a framework for the study of professional discourses has been suggested. Besides, some frequent-occurred phraseologies have been signalled out with the help of a corpus. It is expected that the present study could shed some light on researches in professional discourses and the training of novice professionals with communication skills, because intertextuality is a significant component of professional communicative competence, it is a skill that novice professionals are encouraged to master. Since politeness is a universal phenomenon, participants of the discourse may tend to be polite for the sake of successful communication. In that sense, the use of "please" and modal verbs could be helpful for the training of professionals.

There are several limitations in the study. Firstly, the size of the data is too small, thus, only a limited amount of phraseologies are found. For this reason, whether the frequently used stems and modal verbs are specific to the communication discourse for translation activity remains unidentified. Secondly, the discourse flow is incomplete, as the telephone calls between editors inside the publishing house have not been recorded. It is hoped that future studies could avoid these limitations.

\section{References}

Barton, D., \& Hamilton, M. (1998). Local literacies. London: Routledge.

Bhatia, V. (2004). Worlds of written discourse: A genre-based view. London: Continuum.

Candlin, C., \& Maley, Y. (1994). Intertextuality and interdiscursivity in the discourse of alternative dispute resolution. In B. L. Gunnarsson, P. Linell and B. Nordberg (Eds.), The construction of professional discourse (pp. 201-222). Harlow: Longman.

Celce-Murcia, M., \& Olshtain, E. (2000) Discourse and context in language teaching: A guide for language teachers. Cambridge: Cambridge University Press.

Cheng, W. (2009). Professional communicative competences: Four key industries in Hong Kong. In W. Cheng and K. C. C. Kong (Eds.), Professional communication: Collaboration between academics and practitioners (pp. 31-50). Hong Kong: Hong Kong University Press.

Cheng, W., \& Kong, K. C. C. (Eds.). (2009). Professional communication: Collaboration between academics and practitioners. Hong Kong: Hong Kong University Press.

Clark, R., \& Ivanic, R. (1997). The politics of writing. London and New York: Routledge.

Devitt, A. J. (1991). Intertextuality in tax accounting: Generic, referential, and functional. In B. Charles and P. James (Eds.) Textual dynamics of the professions: Historical and contemporary studies of writing in professional communities (pp. 336-357). Wisconsin: University of Wisconsin Press.

Fairclough, N. (1989). Language and power. London: Longman.

Fairclough, N. (1992). Discourse and social change. Cambridge: Polity.

Fairclough, N. (1995). Critical discourse analysis. London: Longman.

Fairclough, N. (2003). Analysing discourse: Textual analysis for social research. London: Routledge.

Gao, H. (1999). Features of request strategies in Chinese. Lund Working Papers in Linguistics, 47, 73-86.

Gunnarsson, B. L. (1997). The writing process from a sociolinguistic viewpoint. Written Communication, 14(2), 139188.

Ho, V. (2011). What functions do intertextuality and interdiscursivity serve in request e-mail discourse?. Journal of Pragmatics, 43(10), 2534-2547. http://doi:10.1016/j.pragma.2011.04.002

Kankaanranta, A. (2006). 'Hej, Seppo. Could you pls comment on this?' — International email communication in lingua franca English in a multinational company. Business Communication Quarterly, 69(2), 216-225.

Lee, C. F. (2004). Written requests in emails sent by adult Chinese learners of English. Language Culture and Curriculum, 17(1), 58-72. http://dx.doi.org/10.1080/07908310408666682

Nickerson, C. (2000). Playing the corporate language game: An investigation of the genres and discourse strategies in English used by Dutch writers working in multinational corporations. Amsterdam and Atlanta: Rodopi.

O’Connor, E. (2002). Storied business: Typology, intertextuality, and traffic in entrepreneurial narrative. Journal of Business Communication, 39(1), 36-54. http://dx.doi.org/10.1177/002194360203900103

Qian, D. D. (2005). Assessing English writing for professional communication: A perspective from employers. Crosslinks in English Language Teaching, 2, 105-122. 
Rosemary, C. A., Roskos, K. A., \& Landreth, L. K. (2007). Designing professional development in literacy: A framework for effective instruction. New York: Guilford Press.

Searle, J. (2010). A lens on literacy: Workplace competence and professional practice. In C. Kanes (Ed.), Elaborating professionalism, innovation and change in professional education (pp. 35-57). London: Springer.

Solin, A. (2004) Intertextuality as mediation: On the analysis of intertextual relations in public discourse. Text, 24(2), 267-296.

Spilka, R. (1993). Writing in the workplace: New research perspectives. Carbondale: Southern Illinois University Press.

Warren, M. (2011). Realisations of intertextuality, interdiscursivity and hybridisation in the discourses of professionals. In G. Garzone and M. Gotti (Eds.) Tension and change in domain-specific genres (pp. 91-110). Frankfurt am Main: Peter Lang.

Warren, M. (2013). "Just spoke to...": The types and directionality of intertextuality in professional discourse. English for Specific Purposes, 32(1), 12-24. http://dx.doi.org/10.1016/j.esp.2012.07.001. 